\title{
Definição de idades ótimas para expedição de mudas de Araucaria angustifolia (Bertol.) Kuntze (Araucariaceae) em função de sua qualidade e volume de recipientes
}

\author{
Lauri Amândio Schorn * \\ Giulia Pandini \\ Ricardo Bittencourt \\ Tatiele Anete B. Fenilli \\ Universidade Regional de Blumenau, Programa de Pós-Graduação em Engenharia Florestal \\ Rua São Paulo, 3250, Campus II da FURB, CEP 89.030-080, Blumenau - SC, Brasil \\ * Autor para correspondência \\ 1schorn@furb.br
}

Submetido em 04/07/2019

Aceito para publicação em 02/10/2019

\section{Resumo}

O experimento teve como objetivo avaliar a qualidade e o desenvolvimento de mudas de Araucaria angustifolia (Bertol.) Kuntze, de diferentes idades e produzidas em diferentes volumes de tubetes, visando determinar a idade ótima de expedição das mudas. Foram usados três volumes de tubetes $\left(50,100 \mathrm{e} 200 \mathrm{~cm}^{3}\right)$, e consideradas quatro idades de expedição ( $90,120,150$ e 180 dias). O delineamento experimental foi inteiramente casualizado, em esquema fatorial $3 \times 2$, com 12 tratamentos e cinco repetições por tratamento, totalizando 2.400 plantas no experimento. As avaliações foram realizadas mensalmente, utilizando-se cinco mudas de cada repetição e selecionadas aleatoriamente. Foram mensuradas e determinadas as seguintes variáveis em cada ocasião: altura, diâmetro do coleto, massa seca de raízes, massa seca aérea, número de raízes secundárias e índice de qualidade de Dickson. Somente as variáveis altura, massa seca aérea e número de raízes secundárias apresentaram diferenças significativas entre os tratamentos. As idades consideradas ótimas para expedição das mudas de araucária foram de 120 dias, quando em tubete de $50 \mathrm{~cm}^{3}$, e de 150 dias, quando em tubete de $100 \mathrm{~cm}^{3}$. Para a manutenção de mudas em viveiro por períodos superiores a 150 dias, o uso de tubetes de com volume de $200 \mathrm{~cm}^{3}$ foi considerado mais adequado.

Palavras-chave: Crescimento; Massa Seca; Raízes; Viveiro

\section{Abstract}

Definition of optimal ages for transfer of seedlings of Araucaria angustifolia (Bertol.) Kuntze (Araucariaceae) according to their quality and volume of containers. The objective of this study was to evaluate the quality and development of Araucaria angustifolia (Bertol.) Kuntze seedlings, considering different ages and their growth in different size tube, aiming to determine the optimal age for transfer of nursery seedlings. Three volumes of tubes (50, 100 and $\left.200 \mathrm{~cm}^{3}\right)$ were used and four transfer ages $(90,120,150$ and 180 days) were tested. The study was conducted using a completely randomized design with $3 \times 2$, factorial arrangement of 
treatments, five replications per treatment and a total of 2,400 plants. The evaluations were performed monthly, using five seedlings of each repetition and randomly selected. The following variables were determined on each occasion: height, stem diameter, root dry mass, aerial dry mass, number of secondary roots and Dickson quality index. Only the variables height, aerial dry mass and number of secondary roots showed significant differences between treatments. The ages found to be optimal for the transfer of the araucaria seedlings were 120 days when in a $50-\mathrm{cm}^{3}$ tubes and 150 days when in $100-\mathrm{cm}^{3}$ tubes. For seedling maintenance in nurseries for periods longer than 150 days, the use of $200-\mathrm{cm}^{3}$ tubes was found more appropriate.

Key words: Dry mass; Growth; Nursery; Roots

\section{Introdução}

Araucaria angustifolia (Bertol.) Kuntze é uma espécie característica da Floresta Ombrófila Mista (VELOSO et al., 1991), sendo também encontrada nas áreas de tensão ecológica na Floresta Estacional Semidecidual e na Floresta Ombrófila Densa (CARVALHO, 2003). Estima-se que originalmente havia próximo de 20 milhões de hectares cobertos pela Floresta de Araucária (GUBERT FILHO, 1990).

Devido ao declínio das populações e dos descritores de diversidade genética da espécie, desde 1992 a $A$. angustifolia é tida como ameaçada de extinção no Brasil, e desde 2014 em Santa Catarina. A principal causa da decadência das populações e da diversidade genética foi a intensa exploração madeireira com fins comerciais (MARTINELLI; MORAES, 2013; CONSEMA, 2014; MMA, 2014).

O consumo crescente de produtos oriundos de florestas, e em especial a coleta e consumo de pinhões, origina uma demanda de novos plantios dessa espécie, seja através de reflorestamentos homogêneos ou pelo enriquecimento de florestas em estágio inicial de desenvolvimento. Dentro desse contexto está a produção de mudas florestais e a importância de estudos que possibilitem melhor eficiência da produção para o atendimento dessas demandas.

$\mathrm{Na}$ fase de produção de mudas de qualquer espécie sempre se deve almejar um padrão de qualidade que possibilite o melhor crescimento e a maior sobrevivência no plantio em campo (CARNEIRO, 1995). Várias práticas culturais contribuem para isso, podendo-se citar dentre estas, o manejo da irrigação, fertilização, sombreamento, micorrização, podas, aclimatação, seleção, tipo de recipiente, densidade de cultivo, transporte, armazenamento, dentre outros (ARAÚJO et al., 2018).

O tipo de recipiente e suas dimensões exercem influências sobre a qualidade e os custos de produção de mudas. Os volumes dos recipientes influenciam a disponibilidade de nutrientes e água, devendo ser ressaltado que o maior volume promove a melhor arquitetura do sistema radicular.

Entre as vantagens técnicas do uso do sistema de produção de mudas em tubetes, Santos et al. (2000) relacionam as seguintes: possibilitar a formação do sistema radicular sem enovelamento e crescimento inicial mais rápido logo após o plantio. Da mesma forma, Gonçalves (1995) relatou que a utilização de tubetes de polipropileno, como recipiente de cultivo, permite elevar o grau de automatização dos viveiros florestais, reduzir custos e tempo de produção das mudas, ao mesmo tempo em que se observa uma crescente melhoria do padrão da qualidade destas.

Nesse sentido, o estudo das dimensões adequadas de recipientes para produção de mudas reveste-se de grande importância, pois recipientes com volume superior ao indicado provocam gastos desnecessários, elevam a área do viveiro, aumentam os custos de transporte, manutenção e distribuição das mudas no campo (CARNEIRO, 1995). Já a redução da capacidade dos recipientes, até um limite mínimo, provoca uma maior diferenciação do sistema radicular, o que origina uma maior quantidade de radicelas e pêlos absorventes, aumentando as possibilidades de as plantas obterem os nutrientes necessários (ARAÚJO et al., 2018).

Por outro lado, um dos problemas detectados nas mudas produzidas em recipientes de paredes rígidas são as deformações radiculares, acentuadas pelo pequeno 
volume de substrato que comportam. Essas deformações tendem a continuar após a fase de viveiro, o que acarreta maiores custos na implantação florestal (MATTEI, 1993; FREITAS et al., 2005; NEVES et al., 2005). Esses autores destacaram ainda a importância de se priorizar metodologias de produção de mudas que não provoquem deformações em suas raízes.

No entanto, outros autores obtiveram resultados e conclusões diferentes. Cunha et al. (2005), analisando o efeito das dimensões de recipientes na qualidade de mudas de Handroanthus chrysotrichus (Mart. ex A.DC.) Mattos, concluíram que o desenvolvimento em altura das mudas nos recipientes de maiores dimensões foi superior. Davide e Faria (2008) mencionaram que, dependendo da espécie, devem-se utilizar tubetes de maiores ou menores dimensões, destacando que as espécies florestais pioneiras, normalmente, podem ser produzidas em tubetes de menores dimensões. Assim, torna-se importante estudar qual o tamanho de tubete mais adequado para cada espécie e idade, visando otimizar o espaço no viveiro, os custos de produção e a qualidade das mudas.

Diante do exposto, o objetivo desta pesquisa foi avaliar a qualidade de mudas de A. angustifolia, submetidas a diferentes tamanhos de tubetes de polipropileno, visando determinar a idade ótima de expedição das mudas para cada tamanho de recipiente estudado.

\section{Material e Métodos}

A pesquisa foi desenvolvida no viveiro florestal do laboratório de silvicultura da Universidade Regional de Blumenau (FURB), situado no bairro Fortaleza, em Blumenau-SC. Para o desenvolvimento do estudo foram utilizadas sementes de $A$. angustifolia, provenientes da região de Campo Belo do Sul, em Santa Catarina.

Foram implantados e analisados doze tratamentos, caracterizados pela semeadura e produção de mudas em tubetes com as seguintes dimensões e idades de avaliações: T1 - Tubetes de 3,2 x 12,0 (50 $\left.\mathrm{cm}^{3}\right)$ avaliadas aos 90 dias; T2 - Tubetes de 3,2 x 12,0 (50 $\mathrm{cm}^{3}$ ) avaliadas aos 120 dias; T3 - Tubetes de 3,2 x 12,0 $\left(50 \mathrm{~cm}^{3}\right)$ avaliadas aos 150 dias; T4 - Tubetes de 3,2 $\mathrm{x}$
12,0 $\left(50 \mathrm{~cm}^{3}\right)$ avaliadas aos 180 dias; T5 - Tubetes de 4,0 x 14,0 $\left(100 \mathrm{~cm}^{3}\right)$ avaliadas aos 90 dias; T6 - Tubetes de 4,0 x 14,0 $\left(100 \mathrm{~cm}^{3}\right)$ avaliadas aos 120 dias; T7 Tubetes de 4,0 x 14,0 $\left(100 \mathrm{~cm}^{3}\right)$ avaliadas aos 150 dias; T8 - Tubetes de 4,0 x 14,0 $\left(100 \mathrm{~cm}^{3}\right)$ avaliadas aos 180 dias; T9 - Tubetes de 6,0 x 19,0 cm $\left(200 \mathrm{~cm}^{3}\right)$ avaliadas aos 90 dias; T10 - Tubetes de 6,0 x 19,0 cm $\left(200 \mathrm{~cm}^{3}\right)$ avaliadas aos 120 dias; T11 - Tubetes de $6,0 \times 19,0 \mathrm{~cm}$ $\left(200 \mathrm{~cm}^{3}\right)$ avaliadas aos 150 dias; T12 - Tubetes de 6,0 x $19,0 \mathrm{~cm}\left(200 \mathrm{~cm}^{3}\right)$ avaliadas aos 180 dias.

Para todos os tratamentos foi utilizado o substrato contendo matéria orgânica (esterco bovino), solo de horizonte B e casca de arroz carbonizado, na proporção de 2:1:1. O delineamento experimental foi inteiramente casualizado, em fatorial 3x4 (três volumes de tubetes e quatro idades), totalizando doze tratamentos e cinco repetições por tratamento. Cada parcela foi composta por quarenta plantas, acondicionadas individualmente nos respectivos recipientes, totalizando 200 plantas por tratamento e 2.400 plantas no experimento. Para evitar o efeito de borda, foi acrescentada uma fila de plantas nas bordas de cada parcela, as quais não foram avaliadas.

As avaliações foram realizadas aos 90, 120, $150 \mathrm{e}$ 180 dias após a semeadura, utilizando-se cinco mudas de cada repetição. Foram mensuradas em cada muda as seguintes variáveis: altura $(\mathrm{cm})$, diâmetro do coleto $(\mathrm{mm})$, massa seca de raízes $(\mathrm{g})$, massa seca aérea $(\mathrm{g})$, número de raízes secundárias e índice de qualidade de Dickson. Aos 90 dias foi realizada apenas a mensuração das alturas das plântulas, pois parte destas encontravamse ainda em fase de conclusão da germinação. Nos demais períodos foram mensuradas e analisadas também as demais variáveis.

O índice de qualidade de Dickson (ID) foi obtido de acordo com a expressão:

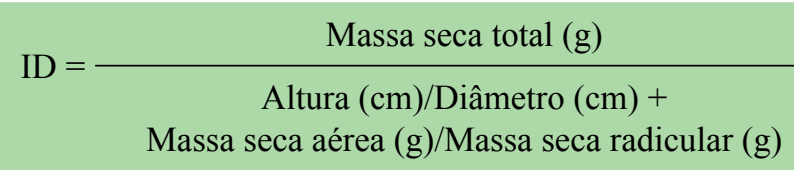

A secagem do material para a obtenção de massa seca foi realizada em estufa a $70^{\circ} \mathrm{C}$ até a obtenção de peso constante. 
Foram realizados os testes de normalidade dos dados através do teste de Bartlett, e de homogeneidade da variância, ambos através do software PAST.

Para realizar a comparação entre os tratamentos foi realizada a análise da variância e as médias comparadas pelo teste de Tukey, utilizando-se o nível de probabilidade de erro de $5 \%$.

\section{Resultados}

$\mathrm{O}$ teste de normalidade dos dados apresentou valores de $\mathrm{P}>0,05$ para todas as variáveis, indicando que os dados seguem a distribuição normal. Já o teste de homogeneidade da variância apresentou valores que rejeitam a hipótese nula, ou seja, $\mathrm{p}>0,05$.
A Tabela 1 apresenta os valores dos parâmetros biométricos avaliados no final do experimento. Foram usadas as médias de interação entre os dois fatores. Observou-se que houve diferença significativa entre os tratamentos a um nível de 5\% de significância para as variáveis altura $(\mathrm{H})$, massa seca aérea (MSA) e número de raízes secundárias.

Os tratamentos mostraram diferenças significativas nas médias de alturas das mudas somente a partir de 150 dias. Nessa idade, as mudas em tubetes com 100 $\mathrm{cm}^{3}$ foram significativamente superiores às mudas produzidas em tubetes com $50 \mathrm{~cm}^{3}$. Já aos 180 dias, tanto as mudas em tubetes com volumes de $100 \mathrm{~cm}^{3}$ quanto aquelas em tubetes com $200 \mathrm{~cm}^{3}$ diferenciaramse significativamente daquelas produzidas em tubetes com $50 \mathrm{~cm}^{3}$.

TABELA 1: Resultados dos parâmetros biométricos em mudas de Araucaria angustifolia através das médias de interações dos fatores, volumes de tubetes e idades

\begin{tabular}{|c|c|c|c|c|c|}
\hline \multirow{2}{*}{ Variáveis biométricas } & \multirow{2}{*}{$\begin{array}{l}\text { Volumes de } \\
\text { tubetes }\left(\mathrm{cm}^{3}\right)\end{array}$} & \multicolumn{4}{|c|}{ Idades (dias) } \\
\hline & & 90 & 120 & 150 & 180 \\
\hline \multirow{3}{*}{$\mathrm{H}(\mathrm{cm})$} & 50 & $1,937 \mathrm{a}$ & $6,658 \mathrm{a}$ & $15,625 \mathrm{~b}$ & $22,215 \mathrm{~b}$ \\
\hline & 100 & $1,904 \mathrm{a}$ & $7,850 \mathrm{a}$ & $15,938 \mathrm{ab}$ & $24,180 \mathrm{a}$ \\
\hline & 200 & $1,839 \mathrm{a}$ & $7,504 \mathrm{a}$ & $17,084 \mathrm{a}$ & $24,585 \mathrm{a}$ \\
\hline \multirow{3}{*}{$\mathrm{D}(\mathrm{cm})$} & 50 & & 0,6222 & 0,6472 & 0,6664 \\
\hline & 100 & & 0,6096 & 0,6250 & 0,6829 \\
\hline & 200 & & 0,5694 & 0,6398 & 0,6619 \\
\hline \multirow{3}{*}{$\operatorname{MSR}(\mathrm{g})$} & 50 & & 0,5828 & 0,6215 & 0,5755 \\
\hline & 100 & & 0,6300 & 0,5480 & 0,4775 \\
\hline & 200 & & 0,5775 & 0,5390 & 0,4920 \\
\hline \multirow{3}{*}{$\operatorname{MSA}(\mathrm{g})$} & 50 & & $0,3670 \mathrm{a}$ & $0,9015 \mathrm{a}$ & $1,2905 \mathrm{c}$ \\
\hline & 100 & & $0,4455 \mathrm{a}$ & $0,8715 \mathrm{a}$ & $1,5360 \mathrm{~b}$ \\
\hline & 200 & & $0,3645 \mathrm{a}$ & $0,9600 \mathrm{a}$ & $1,6995 \mathrm{a}$ \\
\hline \multirow{3}{*}{ Raízes secundárias (n) } & 50 & & $20,90 \mathrm{~b}$ & $22,80 \mathrm{a}$ & $18,90 \mathrm{~b}$ \\
\hline & 100 & & $21,90 \mathrm{ab}$ & $22,30 \mathrm{a}$ & $21,40 \mathrm{~b}$ \\
\hline & 200 & & $24,85 \mathrm{a}$ & $24,65 \mathrm{a}$ & $29,75 \mathrm{a}$ \\
\hline \multirow{3}{*}{ IQD } & 50 & & 0,0873 & 0,0603 & 0,0524 \\
\hline & 100 & & 0,0815 & 0,0523 & 0,0552 \\
\hline & 200 & & 0,0701 & 0,0535 & 0,0535 \\
\hline
\end{tabular}

Parâmetros biométricos: H (cm) altura da parte aérea das mudas; D (cm) diâmetro do coleto; MSA (g) massa seca da parte aérea; MSR (g) massa seca das raízes; MST (g) massa seca total; Raízes secundárias (média do número de raízes secundárias); IQD Índice de Qualidade de Dickson. As médias seguidas pela mesma letra nas colunas não diferem estatisticamente entre si. Foi aplicado o Teste de Tukey ao nível de $5 \%$ de probabilidade. Variáveis biométricas com médias sem letras indicam que as diferenças não foram significativas. 
Na Figura 1, estão ilustrados os incrementos em alturas obtidos para as mudas de araucária nos três volumes de tubetes e as respectivas equações geradas a partir de seus valores. As mudas produzidas em tubetes de $50 \mathrm{~cm}^{3}$ apresentaram incremento máximo em altura na idade de 150 dias. Já aquelas produzidas em tubetes de 100 e de $200 \mathrm{~cm}^{3}$ obtiveram o incremento máximo aos 165 dias. Os valores máximos estimados para incrementos em alturas das mudas por mês foram de 7,4 $\mathrm{cm}, 8,2 \mathrm{~cm}$ e $8,4 \mathrm{~cm}$, para tubetes de $50 \mathrm{~cm}^{3}, 100 \mathrm{~cm}^{3} \mathrm{e}$ $200 \mathrm{~cm}^{3}$, respectivamente.

Considerando as diferenças observadas nas alturas das mudas (Tabela 1), verifica-se que a produção em tubetes de $200 \mathrm{~cm}^{3}$, embora também tenha atingido o máximo incremento aos 165 dias, não foi significativamente superior em altura em relação à produção em tubetes de $100 \mathrm{~cm}^{3}$, verificando-se o mesmo comportamento até os 180 dias. Dessa forma, para manutenção de até seis meses, em viveiro, pode-se usar tubetes com $100 \mathrm{~cm}^{3}$. O maior período necessário para atingir o máximo incremento em tubetes com 100 e $200 \mathrm{~cm}^{3}$ pode estar relacionado ao início da limitação ao desenvolvimento radicular mais tardio. Esse fato foi constatado por Freitas et al. (2006), que considerou a restrição do crescimento das mudas em viveiro em função do volume de recipiente utilizado, e também por Barroso et al. (2000), que observaram comportamento semelhante na produção de mudas de Eucaliptos em recipientes de diferentes volumes.

Os incrementos em diâmetro do coleto obtidos para as mudas de araucária, nos três volumes de tubetes, mostraram que os valores máximos foram obtidos até 120 dias, declinando acentuadamente após essa idade (Figura 2). As equações ajustadas para os três volumes de tubetes resultaram em valores médios de $\mathrm{R}^{2}$, indicando dispersão dos dados de incrementos em diâmetro. Os valores máximos obtidos para incrementos em diâmetro das mudas foram de $0,46,0,44$ e $0,43 \mathrm{~mm}$ por mês, para tubetes de 50,100 e $200 \mathrm{~cm}^{3}$, respectivamente.

Para a variável massa seca aérea (MSA) as mudas não apresentaram diferenças significativas até a idade de 150 dias. Somente aos 180 dias observou-se distinção entre os tratamentos, quando as mudas produzidas em tubetes maiores $\left(200 \mathrm{~cm}^{3}\right)$ foram significativamente superiores às demais (Tabela 1). Esse resultado reforça o que foi observado para as médias das alturas, em que mudas em tubetes de $50 \mathrm{~cm}^{3}$ aos 180 dias sofreram restrição do crescimento.

FIGURA 1: Incremento em altura $(\mathrm{cm})$ de mudas de Araucaria angustifolia produzidas em três volumes de tubetes.

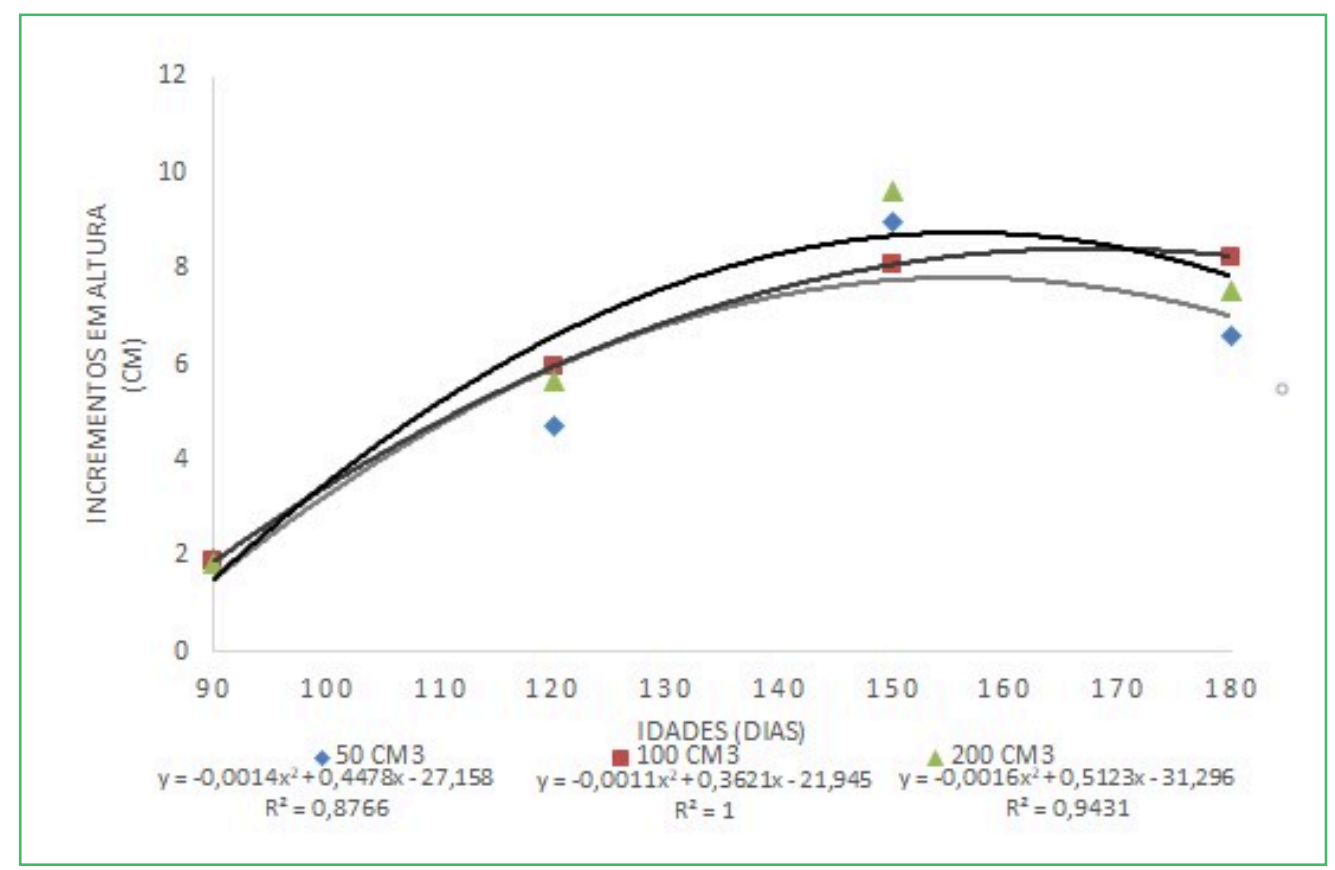


FIGURA 2: Incrementos em diâmetro (mm) de mudas de Araucaria angustifólia produzidas em três volumes de tubetes.

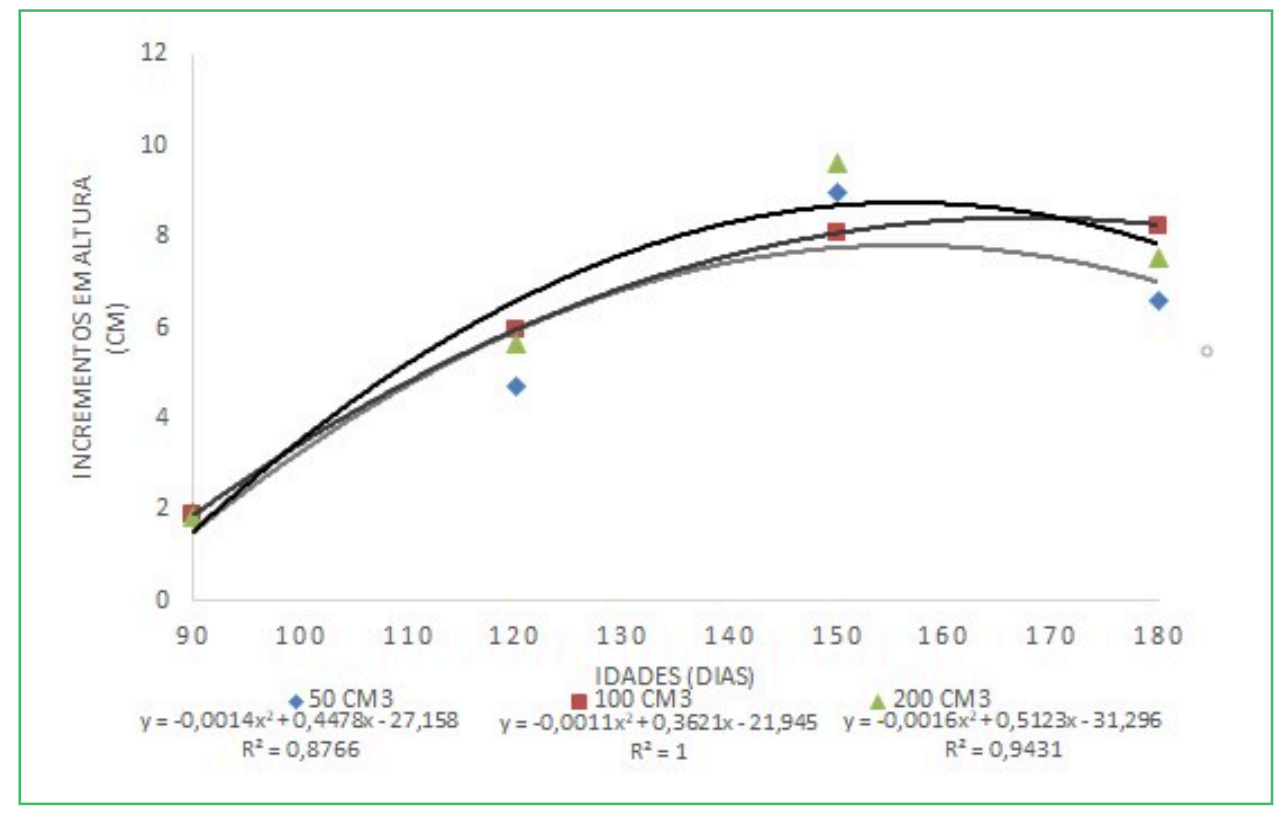

Em relação ao número de raízes secundárias, observaram-se diferenças entre os tratamentos a partir de 120 dias, quando as mudas em tubetes maiores mostraram valores superiores para esse atributo. Já aos 150 dias, os valores obtidos para essa variável não se diferenciaram significativamente, enquanto aos 180 dias observaram-se novamente valores crescentes em número de raízes secundárias, dos menores para os maiores tubetes, indicando a ocorrência de restrição ao desenvolvimento radicular nas mudas em tubetes menores que $200 \mathrm{~cm}^{3}$.

Para as demais variáveis analisadas, diâmetro do coleto, massa seca de raízes e índice de qualidade de Dickson, não foram observadas diferenças significativas entre os tratamentos, bem como para as interações entre os fatores tamanhos de tubetes e idades das mudas.

\section{Discussão}

Os resultados evidenciaram que os tratamentos em tubetes de $50 \mathrm{~cm}^{3}$ passaram a restringir o crescimento das mudas a partir da idade de 150 dias. Por consequência, considerando a variável altura das mudas, o tubete com $50 \mathrm{~cm}^{3}$ só deve ser recomendado para idades de até 120 dias de permanência no viveiro. Os resultados obtidos são convergentes com aqueles relatados por Cunha et al. (2005) para Handroanthus chrysotrichus (Mart. ex A.DC.) Mattos. No entanto, conforme relatou Parviainen (1981), apesar de a altura ser considerada como um dos parâmetros mais antigos, usados na classificação e seleção de mudas, devem-se considerar outros fatores (GOMES; PAIVA, 2011). Observação semelhante foi relatada por Carneiro (1995) ao mencionar que a variável altura, quando utilizada isoladamente, não representa o real potencial das mudas. Segundo o autor, mudas mais altas somente apresentaram maior sobrevivência e crescimento quando associadas aos maiores diâmetros de coleto.

Considerando as diferenças observadas nas alturas das mudas (Tabela 1), verifica-se que a produção em tubetes de $200 \mathrm{~cm}^{3}$, embora também tenha atingido o máximo incremento aos 150 dias, foi significativamente superior em altura em relação à produzida em tubetes de $50 \mathrm{~cm}^{3} \mathrm{O}$ maior período necessário para atingir o máximo incremento em tubetes com $100 \mathrm{~cm}^{3}$ pode estar relacionado ao início da limitação ao desenvolvimento radicular. Esse fato foi constatado por Freitas et al. (2006), que considerou a restrição do crescimento das mudas em viveiro em função do volume de recipiente utilizado; e ainda por Barroso et al. (2000), que 
observaram comportamento semelhante na produção de mudas de Eucaliptos em recipientes de diferentes volumes.

De acordo com Knapik (2005) e Gomes e Paiva (2011), o diâmetro de coleto é tido como a característica morfológica que melhor se ajusta aos modelos de predição de sobrevivência e crescimento das mudas em campo. Neste estudo, porém, não houve diferença significativa entre tratamentos quanto ao diâmetro de coleto das mudas. Pode-se considerar que essa variável, para a espécie estudada, não foi afetada pelos dois fatores analisados, pois os volumes de tubetes e o tempo de permanência no viveiro não alteraram significativamente o diâmetro do coleto das mudas. Para esse resultado não se pode descartar a influência do volume de reservas no endosperma das sementes de araucária, que poderiam contribuir para o desempenho inicial das mudas. No entanto, o efeito do endosperma no desempenho inicial das mudas somente pode ser confirmado em estudos que incluam essa avaliação.

A massa seca das raízes também não variou significativamente entre tratamentos. Esse fato é convergente com resultados obtidos para essa variável em outros trabalhos. Reis et al. (1989) observaram que a restrição imposta pelo recipiente promoveu o crescimento balanceado entre as partes aérea e radicular de mudas de eucalipto, sem alteração na distribuição relativa de massa seca com a variação do volume do tubete. José et al. (2005) também não constataram diferenças significativas dessa relação em mudas de aroeira-vermelha Schinus terebinthifolius Raddi produzidas em tubetes com volumes de 50 e $150 \mathrm{~cm}^{3}$.

Outros autores (GOMES; PAIVA, 2011; ARAÚJO et al., 2018) observam que a MSA indica a rusticidade das mudas, enquanto a MSR representa um atributo relacionado com a sobrevivência e o crescimento inicial em campo. Os mesmos autores destacam que maiores valores de MSR podem ser resultado da lignificação de raízes, assim como a maior espessura, devido à permanência no viveiro por tempo que excede a capacidade do recipiente, justificando a necessidade de analisar outros atributos como o comprimento de raízes ou ainda o número de raízes.
Os resultados obtidos para o diâmetro do coleto e para o IQD são coerentes com as observações de Binotto et al. (2010), que, ao estudarem a correlação entre oito características de crescimento e o índice de qualidade de Dickson (IQD) em mudas de Eucalyptus grandis Hill ex Maiden e Pinus elliottii var. elliottii, concluíram que o diâmetro de coleto é a variável de maior correlação com o IQD. A elevada relação entre essas variáveis pode explicar o fato de elas não terem sido influenciadas pelos volumes dos tubetes e idades das mudas, pois, conforme relatado por Araújo et al. (2018), entre os atributos que contribuem para a elevação do IQD está a maior MSR.

Diante dos resultados obtidos, é possível verificar que a produção de mudas de $A$. angustifolia pode ser realizada em tubetes de $50 \mathrm{~cm}^{3}$ até o período de 120 dias, quando as mudas atingem valores de alturas entre 15 a 18 $\mathrm{cm}$. No entanto, para a obtenção de mudas com maiores alturas e que demandam maior período em viveiro, torna-se necessário o uso de tubetes de maiores volumes.

Os tubetes de $100 \mathrm{~cm}^{3}$ provocaram restrições para o desenvolvimento da massa seca aérea e o número de raízes secundárias aos 180 dias, evidenciando que esse volume de tubete, nessa idade, já não é o mais recomendado para as mudas de araucária. Os resultados obtidos para as variáveis das mudas, altura, massa seca aérea e raízes secundárias sugerem que somente mudas de $A$. angustifolia produzidas em tubetes de $200 \mathrm{~cm}^{3}$ podem permanecer em viveiro por períodos superiores a 150 dias.

Resultados convergentes foram encontrados por Yuyama e Siqueira (1999) em mudas de Myrciaria dubia (H.B.K.) Mc Vaugh e por Oliveira et al. (2000) em mudas de Anacardium occidentale L. De forma semelhante, Malavasi e Malavasi (2006) obtiveram melhor desempenho no desenvolvimento de mudas de Cordia trichotoma (Vell.) Arráb. Ex Steud e de Jacaranda micrantha Cham. em tubetes com 120, 180 e $300 \mathrm{~cm}^{3}$ quando comparadas com mudas produzidas em tubetes de $50 \mathrm{~cm}^{3}$, após 180 dias do plantio a campo.

De forma geral, os resultados também são amparados pelas considerações de Wendling e Delgado (2008), que recomendam, para a produção de mudas de araucária, o uso de tubetes de no mínimo $100 \mathrm{~cm}^{3}$. 
Esses autores ressaltaram ainda que quanto maior o tamanho do recipiente, mais tempo as mudas podem permanecer no viveiro, porém aumentam também os custos de produção.

Os resultados permitem concluir que as idades adequadas para expedição de mudas de $A$. angustifolia, considerando a sua qualidade, são dependentes do volume de tubetes e, portanto, da quantidade de substrato à disposição das mudas. Desta forma, mudas de $A$. angustifolia produzidas em tubetes de $50 \mathrm{~cm}^{3}$ podem permanecer em viveiro até a idade de 120 dias, enquanto mudas produzidas em tubetes de $200 \mathrm{~cm}^{3}$ podem permanecer em viveiro com idades superiores a 150 dias.

As variáveis diâmetro do coleto, massa seca radicular e índice de qualidade de Dickson não sofreram influências de volumes de tubetes e das idades das mudas no período avaliado. Sugere-se a realização de outros estudos com a espécie, abrangendo maior período de avaliação e incluindo outros volumes de recipientes.

\section{Referências}

ARAÚJO, M. M.; NAVROSKI, M. C.; SCHORN, L. A.; TABALDI, L. A.; RORATO, D. G.; TURCHETTO, F.; ZAVISTANOVICZ, T. C.; BERGHETTI, A. L. P.; AIMI, S. C.; TONETTO, T. da S.; GASPARIN, E.; DUTRA, A. F.; MEZZOMO, J. C.; GOMES, D. R.; GRIEBELER, A. M.; SILVA, M. R. da; BARBOSA, F. M.; LIMA, M. S. de. Caracterização e análise de atributos morfológicos e fisiológicos indicadores da qualidade de mudas em viveiro florestal. In: ARAÚJO, M. M.; NAVROSKI, M.; SCHORN, L. A. (Ed.). Produção de sementes e mudas: um enfoque à silvicultura. Santa Maria: Editora UFSM, 2018. p. 345-382.

BARROSO, D. G.; CARNEIRO, J. G. de A.; NOVAES, A. B. de; LELES, P. S. dos S. Efeitos de recipientes sobre o desempenho pós-plantio de Eucalyptus camaldulensis Dehnh e E. urophyla S. T. Blake. Revista Árvore, Viçosa, v. 24, n. 32, p. 291-296, 2000.

BINOTTO, A. F.; LÚCIO, A. D.; LOPES, S. J. Correlations between growth variables and the dickson quality índex in forest seedlings. Cerne, Lavras, v. 16, n. 4, p. 457-464, 2010.

CARNEIRO, J. G. A. Produção e controle de qualidade de mudas florestais. Curitiba: UFPR/FUPEF, 1995. 451 p.

CARVALHO, P. E. R. Espécies arbóreas brasileiras. Brasília: Embrapa Informação Tecnológica; Colombo: Embrapa Florestas, 2003. 1039 p.

CONSEMA - CONSELHO ESTADUAL DO MEIO AMBIENTE. Resolução no 51, de 05 de dezembro de 2014. 2014. Disponível em: $<$ http://www.fatma.sc.gov.br/upload/Flora/resconsema51.pdf $>$.

CUNHA, A. O.; ANDRADE, L. A. de; BRUNO, R. L. A.; SILVA, J. A. L. da; SOUZA, V. C. de. Efeitos de substratos e das dimensões de recipientes na qualidade de mudas de Tabebuia impetiginosa (Mart. Ex D. C.) Standl. Revista Árvore, Viçosa, v. 29, n. 4, p. 507-516, 2005.

DAVIDE, A. C.; FARIA, J. M. R. Viveiros florestais. In: DAVIDE, A. C.; SILVA, E. A. A. (Ed.). Produção de sementes e mudas de espécies florestais. Lavras: Universidade Federal de Lavras, 2008. p. 83-124.

FREITAS, T. A. S. de; BARROSO, D. G.; CARNEIRO, J. G. de A.; PENCHEL, R. M.; LAMÔNICA, K. R.; FERREIRA, D. de A. Desempenho radicular de mudas de Eucalipto produzidas em diferentes recipientes e substratos. Revista Árvore, Viçosa, v. 29, n. 6, p. 853-861, 2005.

FREITAS, T. A. S.; BARROSO, D. G.; CARNEIRO, J. G. de A.; PENCHEL, R. M.; FIGUEIREDO, F. A. M. M. de A. Mudas de eucalipto produzidas a partir de miniestacas em diferentes recipientes e substratos. Revista Árvore, Viçosa, v. 30, n. 4, p. 519-528, 2006.

GOMES, J. M.; PAIVA, H. N. Viveiros florestais: propagação sexuada. Viçosa: UFV, 2011. 116 p.

GONÇALVES, J. Produção de mudas de Eucalipto e Pinus usando o sistema de tubetes. In: JORNADAS FORESTALES DE ENTRE RIOS, 10, 1995, Concordia (Argentina). Anais... Concordia: INTA, 1995. p. 1-4.

GUBERT FILHO, F. Proposta para a criação de um sistema de unidades de conservação da Araucaria angustifolia no estado do Paraná. In: CONGRESSO FLORESTAL BRASILEIRO, 6, 1990, Campos do Jordão. Anais... Campos do Jordão: Sociedade Brasileira de Silvicultura, 1990. Vol. 3. p. 287-300.

JOSÉ, A. C.; DA VIDE, A. C.; OLIVEIRA, S. L. Produção de mudas de aroeira (Schinus terebinthifolius Raddi) para recuperação de áreas degradadas pela mineração de bauxita. Cerne, Lavras, v. 11, n. 2, p. 187-196, 2005.

KNAPIK, G. J. Utilização do pó de basalto como alternativa à adubação convencional na produção de mudas de Mimosa scabrella Benth e Prunus sellowii Koehne. 2005. $163 \mathrm{f}$. Dissertação (Mestrado em Engenharia Florestal) - Universidade Federal do Paraná, Curitiba. 2005.

MALAVASI, U. C.; MALAVASI, M. de M. Efeito do volume do tubete no crescimento inicial de plântulas de Cordia trichotoma (Vell.) Arrab. Ex Steud e Jacaranda micrantha Cham. Ciência Florestal, Santa Maria, v. 16, n. 1, p. 11-16, 2006.

MATTEI, V. L. Comparação entre semeadura direta e plantio de mudas produzidas em tubetes, na implantação de povoamento de Pinus taeda L. 1993. 149 f. Tese (Doutorado em Engenharia Florestal) - Universidade Federal do Paraná, Curitiba. 1993.

MARTINELLI, G.; MORAES, M. A. Livro vermelho da Flora do Brasil. 1. ed. Rio de Janeiro: Instituto de Pesquisas Jardim Botânico do Rio de Janeiro, 2013. 1.102 p.

MMA - MINISTÉRIO DO MEIO AMBIENTE. Portaria n⿳4043, de 17 de dezembro de 2014. Diário Oficial da União, seção $1, n^{\circ}$ 245, 18 de dezembro de 2014. p. 110-121.

NEVES, C. S. V. J.; MEDINA, C. de C.; AZEVEDO, M. C. B. de; HIGA, A. R.; SIMON, A. Efeitos de substratos e recipientes utilizados na produção das mudas sobre a arquitetura do sistema radicular de árvores de Acácia-negra. Revista Árvore, Viçosa, v. 29, n. 6, p. 897-905, 2005. 
OLIVEIRA, F. N. S.; LIMA, A. A. C.; AQUINO, A. R. L.; SANTOS, J. L. Manejo sustentável do cajueiro anão precoce enxertado em cultivo orgânico. Fortaleza: Embrapa Agroindústria Tropical, 2000. 3 p.

PARVIAINEN, J. O desenvolvimento radicular das mudas florestais no viveiro e no local de plantio. In: SEMINÁRIO DE SEMENTES E VIVEIROS FLORESTAIS, 1981, Curitiba. Anais... Curitiba: FUPEF, 1981. Vol. 2. p. 111-130.

REIS, G. G.; REIS, M. das G. F.; MAESTRI, M.; XAVIER, A.; OLIVEIRA, L. M. de. Crescimento de Eucalyptus camaldulensis, Eucalyptus grandis e Eucalyptus cloeziana sob diferentes níveis de restrição radicular. Revista Árvore, v. 13, n. 1, p. 1-18, 1989.
SANTOS, C. B.; LONGHI, S. J.; HOPPE, J. M.; MOSCOVICH, F. A. Efeito do volume de tubetes e tipos de substratos na qualidade de mudas de Cryptomeria japonica (L.F.) D. Don. Ciência Florestal, Santa Maria, v. 10, n. 2, p. 1-15, 2000.

VELOSO, H. P.; RANGEL FILHO, A. L. R.; LIMA, J. C. A. Classificação da vegetação brasileira, adaptada a um sistema universal. Rio de Janeiro: Fundação Instituto Brasileiro de Geografia e Estatística, 1991. 123 p.

WENDling, I.; DELGADO, M. E. Produção de mudas de araucária em tubetes. Colombo: Embrapa Florestas, 2008. 8 p. Comunicado Técnico 201.

YUYAMA, K.; SIQUEIRA, J. A. S. Efeito do tamanho das sementes e do recipiente no crescimento de mudas de camu-camu (Myrciaria dúbia). Acta Amazonica, Manaus, v. 29, n. 4, p. 647-650, 1999. 